\title{
Physicians should be paid to report adverse drug reactions, experts say
}

$\mathrm{M}$ andatory physician reporting of adverse drug reactions could strengthen postmarket surveillance of pharmaceuticals in Canada and provide an overhaul of the country's "haphazard" drug safety database, experts say.

But getting physicians to comply with such a mandate will likely require offering cash for filing the reports, they add.

At a minimum, Canada should follow New Zealand's lead and require doctors to report all instances in which one of their patients suffered an adverse effect from the use of a drug or a combination of drugs, says Dr. Sonal Singh, assistant professor of general internal medicine at the Johns Hopkins University School of Medicine in Baltimore, Maryland.

"There should be something, like in New Zealand, where every new prescription you have, you get intensive monitoring," Singh explains. "Every new prescription should have doctors reporting if there was an adverse event or not."

It's estimated one in nine emergency department visits in Canada are due to drug-related adverse events, many of which are potentially preventable (www.cmaj.ca/lookup/doi/10.1503/cmaj .071594).

But it's "difficult to find absolute data" on the number of adverse drug reactions and events that occur in Canada, according to Marg Colquhoun, a project leader at the Institute for Safe Medication Practices Canada.

Although Health Canada requires drug manufacturers to flag suspected adverse reactions to the products they market, physician reporting is entirely voluntary and therefore conditional on doctors having the time and inclination to do the additional paperwork.

As such, the data collected by MedEffect Canada - Health Canada's adverse drug reaction reporting tool for

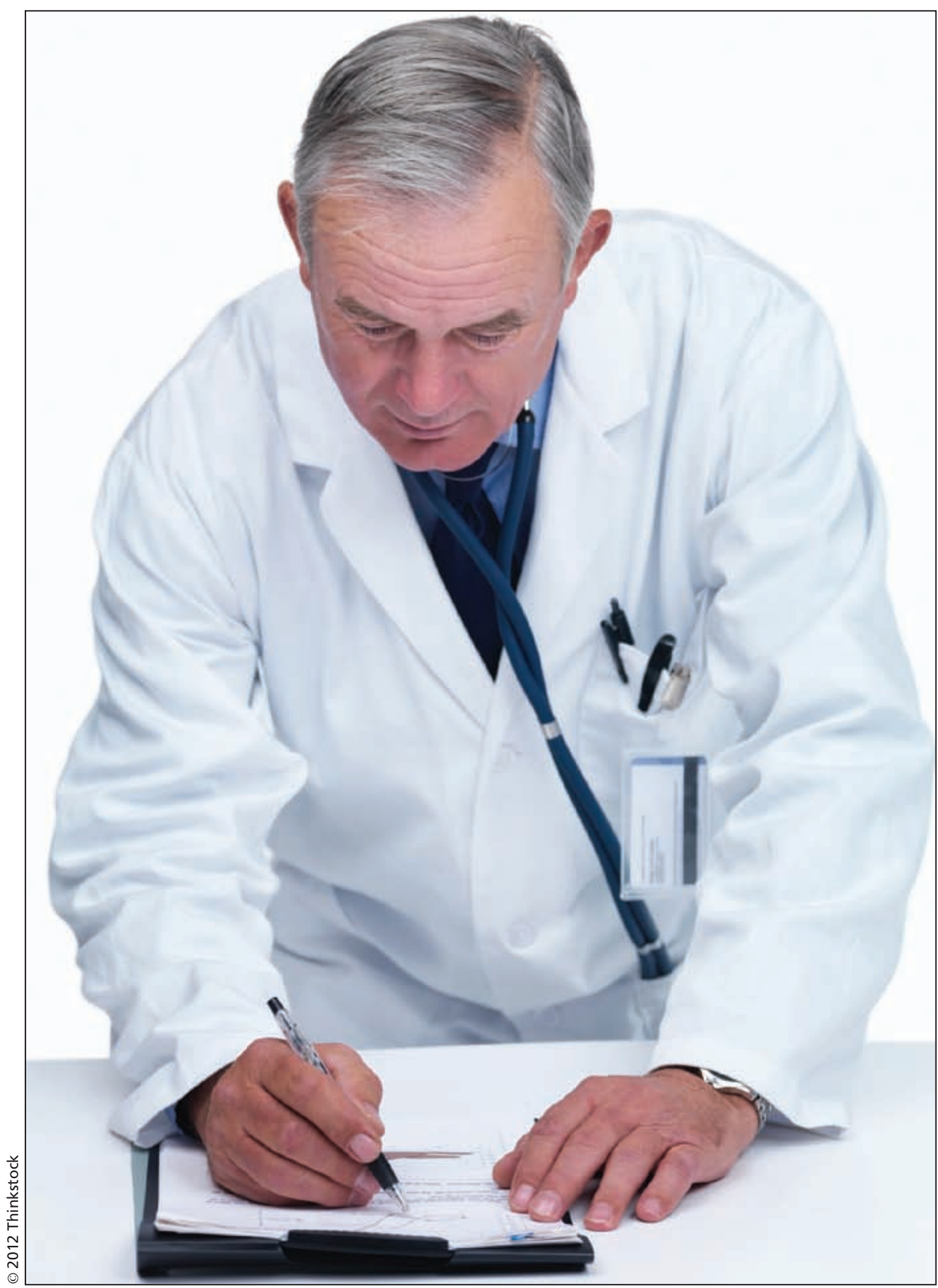

Compelling physicians to report adverse drug reactions would help overhaul the country's drug safety database but also add paperwork.

health professionals and the public are "not very rich," explains Dr. David Juurlink, head of clinical pharmacology and toxicology at Sunnybrook Health Sciences Centre in Toronto, Ontario.

Indeed, the tool itself is so "poorly structured" as to render the information it compiles "often uninterpretable," he says. For example, clinically important information, such as the time between a patient starting a drug and experiencing an adverse effect, must be dumped in "free text" entry fields with a jumble of other information. 
"If someone's on 10 different medications and they have a life-threatening skin reaction, the person who is reading [the resulting report] has no idea which of those drugs might have been at play ... [because] presently that's not easily inferred from the data," Juurlink explains. "It's a little bit a case of garbage in, garbage out."

Linda Wilhelm, an independent member of the Best Medicines Coalition, an alliance of organizations and individuals for the promotion of drug safety, concurs. She says increased reporting by health professionals to MedEffect could fill some of the gaps in current data, but many physicians feel it's largely an exercise in futility because it's not clear how Health Canada uses the information.

"There's been a lot of push-back from the physician community on mandatory reporting because the time it would take for them to do it is quite labour intensive," Wilhelm explains. "Meanwhile, there really isn't any feedback to them about what happens to that information, so they feel like it's going into a big, dark hole."

Even physicians who see the value of reporting to the system can find it difficult to carve out time to flag every suspected adverse drug reaction - particularly as they're not compensated for that time, she adds. "If it's valuable for the physician to complete that form, then they should be compensated for completing it."
Juurlink concurs, adding that such incentives ideally should be introduced in concert with changes to how MedEffect collects and compiles information.

"It should be made easier to report, it should be remunerated and reports should incorporate sufficient clinical detail so that someone on the other end can begin to formulate conclusions about cause and effect," Juurlink explains. "Unless done carefully, we could end up with just more reports of equally uninterpretable information."

"That doesn't mean requiring more data, just having it structured in a way that's more interpretable than what it presently is," he says.

Wilhelm would also like to see increased transparency about how adverse reaction reports inform the postmarket surveillance process.

"Health Canada should provide feedback to the physician about what happened to their report," she argues. "Did they get 300 similar reports from other physicians? Physicians want to know someone's reading them and they've done some good."

In an effort to improve postmarket drug surveillance, Health Canada proposed in 2007 to lower the threshold for initial marketing authorization licenses for drugs in exchange for additional safety and efficacy studies as a condition for continuing to sell a drug (www.cmaj.ca/lookup/doi/10.1503/cmaj .070449).
The department and the Canadian Institutes of Health Research subsequently provided $\$ 32$ million over five years to create a Drug Safety and Effectiveness Network, expected to be operational in fiscal 2012/13, that will gather postmarket drug data. It will consist of a virtual network of centres in excellence in postmarket drug research, a coordinating office to manage network operations and a steering committee to provide strategic direction (www.cmaj.ca/lookup/doi/10.1503/cmaj .109-3103).

It's a drop in the bucket, but better than nothing, says Wilhelm.

Others say the pharmaceutical industry should be willing to pony up some of its profits to establish further effectiveness mechanisms for postmarket surveillance of drugs.

"They're the ones deriving profits," says Juurlink. "They should have a vested interest in making sure their drugs are safe." - L Lauren Vogel, CMAJ and Tomek Sysak, Ottawa, Ont.

CMAJ 2012. DOI:10.1503/cmaj.109-4153

Editor's note: Second of a two-part series.

Part 1: Seeking hard data on adverse effects of drugs

(www.cmaj.ca/lookup/doi/10.1503

/cmaj.109-4152). 